Journal of Chromatography, 197 (1980) 258-262

Elsevier Sciertific Publishing Company, Amsterdam - Printed in The Netherlands

CHROM. 12,949

\title{
Note
}

\section{Gas chromatographic-mass spectrometric analysis of polybrominated bi- phenyl constituents of Firemaster FF-1}

\author{
EDWARD F. DOMINO* and STEVEN E. DOMINO \\ Department of Pharmacology, M6414 Medical Science Building I, Box 035, The University of \\ Michigan, Ann Arbor, MI 48109 (U.S.A.)
}

(First received January 9th, 1980; revised manuscript received May 14th, 1980)

Sundstrom et al. ${ }^{1}$, De Kok et al. ${ }^{2}$, Jacobs et al. ${ }^{3}$, Dannan et al.4 and Willett et al.5 have all reported on the chromatographic characteristics of polybrominated biphenyls (PBBs); surprisingly little has been reported on the gas chromatographicmass spectrometric (GC-MS) characteristics of the PBBs. Firemaster FF-1 was the principal contaminant in the food chain in the State of Michigan in 1973-19746, and it has commonly been assumed that the PBBs alone were the primary toxic agents. We have had an opportunity to examine the GC-MS characteristics of a hexane extract of Firemaster FF-1 and have observed mixed polybromo- and chlorobiphenyls (PBCBs) as minor contaminants in addition to the well-known PBBs.

\section{MATERIALS AND METHODS}

Firemaster FF-1, lot No. FF1312-FT, was obtained from the National Institute of Environmental Health Sciences. A stock solution $(1 \mathrm{mg} / \mathrm{ml})$ in hexane was diluted for subsequent GC-MS analysis. A Finnigan 3200 gas chromatographquadrupole mass spectrometer with a 6100 data system was utilized in these studies. The GC-MS conditions were a column of $3 \%$ of SE-30 on Gas-Chrom Q (100-120 mesh) operated with a column temperature of $180^{\circ} \mathrm{C}$, port and separator temperature $220^{\circ} \mathrm{C}$, analyzer temperature $50^{\circ} \mathrm{C}$ and $100 \%$ helium $(20 \mathrm{ml} / \mathrm{min})$ as the carrier gas. The electron energy was $70 \mathrm{eV}$, and the mass spectrometer was calibrated by using perfluorotributylamine (FC43) from 34 to $614 \mathrm{~m} / \mathrm{e}$. The manufacturer ${ }^{7}$ states that only masses up to 800 a.m.u. are accurately calibrated using FC43. Inasmuch as the heptabromobiphenyls (HpBBs) have a molecular weight of 706.3, this was deemed adequate for determining the major components of PBBs. Next, the high end of the mass spectrum was checked using bis(pentafiuorophenyl)phenylphosphine, better known as decafluorotriphenylphosphine (DFTPP, Ultramark 433) as recommended by Eichelberger et al. ${ }^{8}$.

\section{RESULTS AND DISCUSSION}

The total ion chromatogram (TIC) of $1.5 \mu \mathrm{g}$ of Firemaster FF-1 in hexane is illustrated in Fig. 1a. Peaks were labelled 0 through 10 and their retention times were 


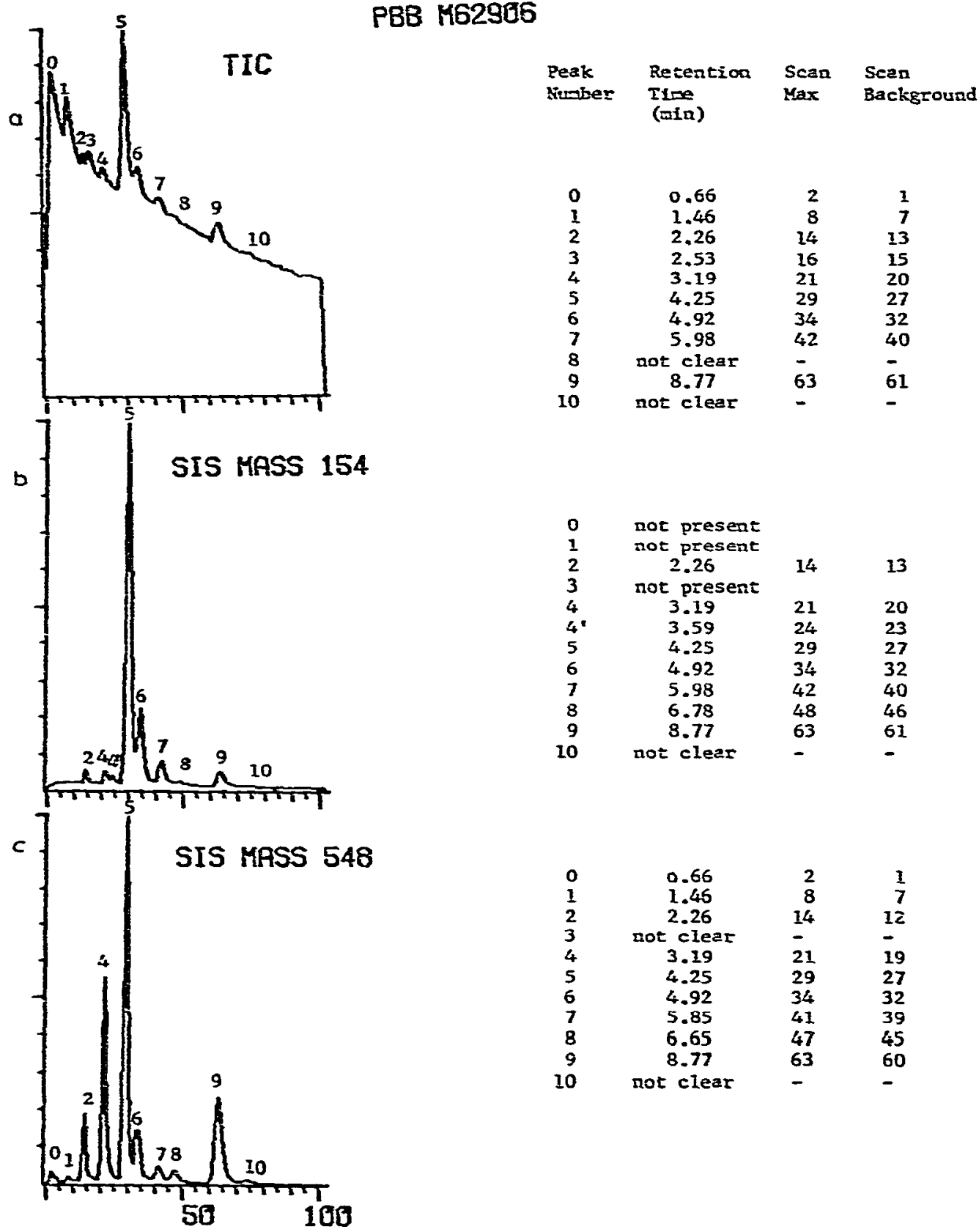

Fig. 1. Total ion chromatogram (TIC) and selected ion seans (SIS) of PBBs in Firemaster FF-1. The upper panel shows the TIC and the lower panels the SIS at m/e 154 and 548 . Peak numbers are as shown. 


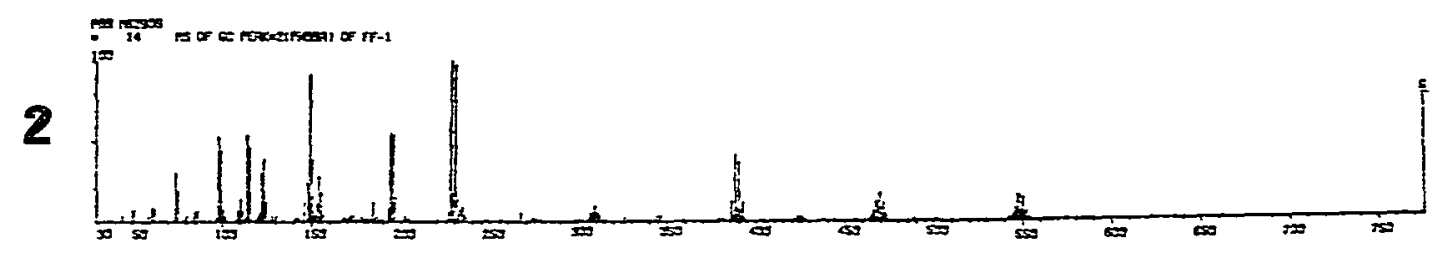

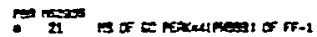

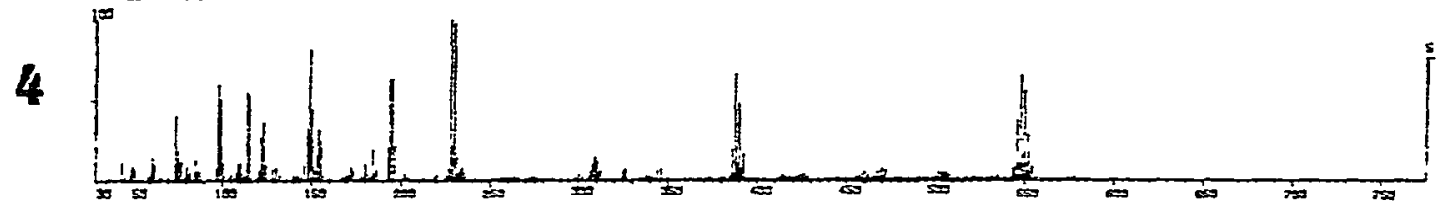

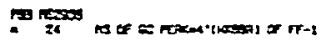

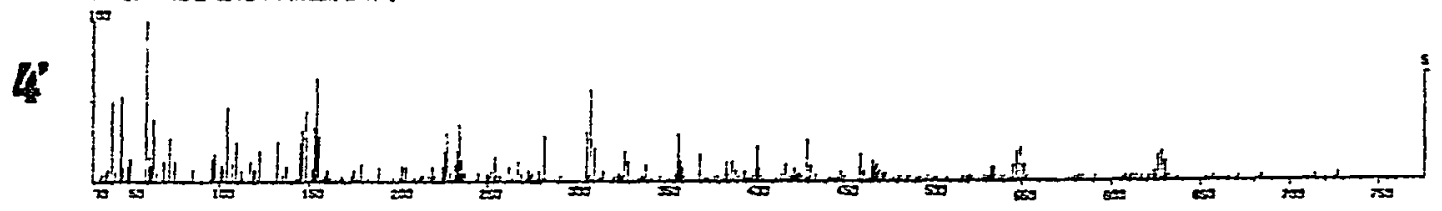

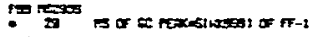

5

is

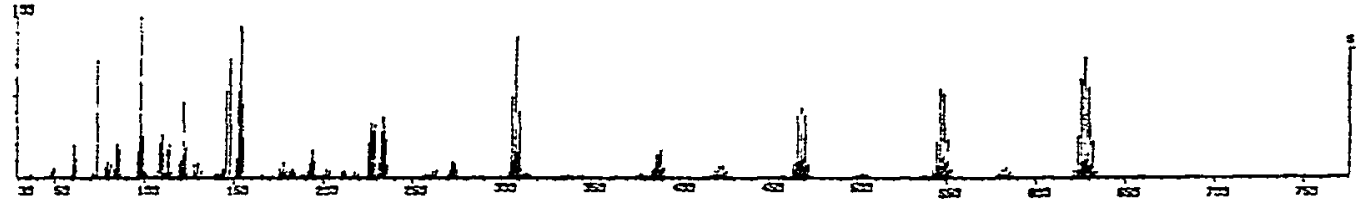

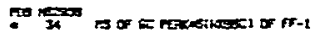

3.
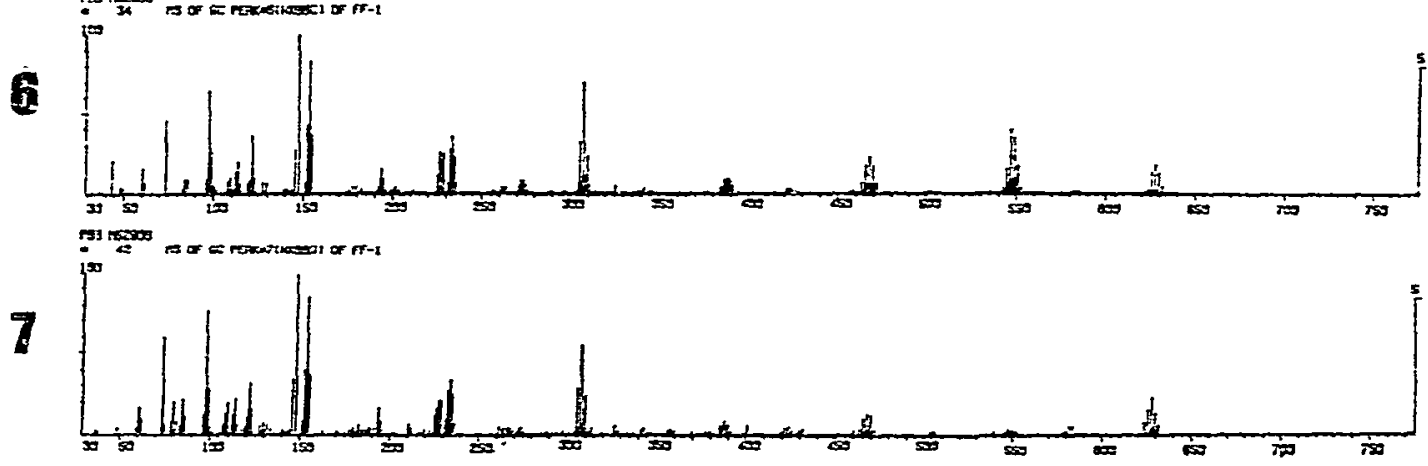

m

3

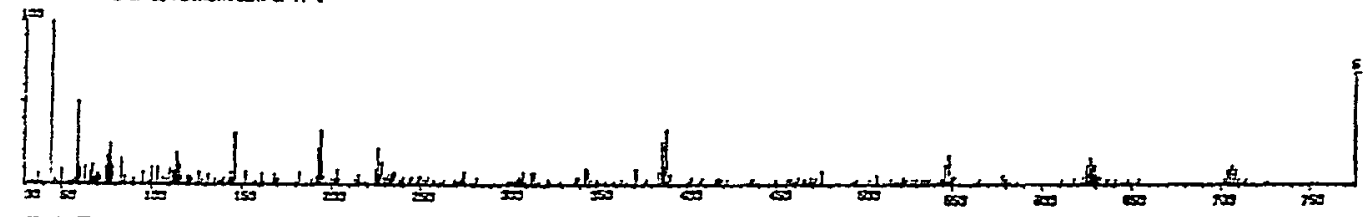
pes

9

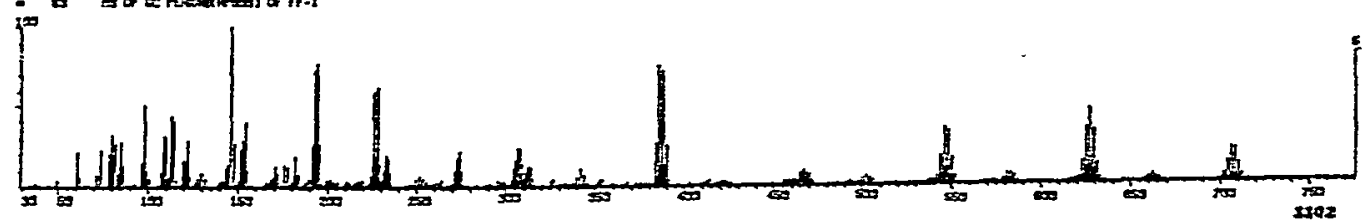

Fig. 2. Mass spectra of the major PBBs in Firemaster FF-1. The mass spectra of the major numbered peaks of the PBBs from Fig. 1 are shown. Note the presence of a chlorine contaminant in the PBBs. See text for details. 
determined. Subsequently, selective ion scans for a.m.u. $98,146,147,148,149,150$, $154,308,547,548$ and 549 were carried out in order to better determine the retention times of ion fragments contained in PBBs, and to better define the specific compounds run as a TIC. The structures of the postulated positive-ion fragments were identified. Fons 154 and 548 were especially helpful, as shown in the selected ion scans (SIS) in Fig. 1b and 1c. The mass spectra for 8 of the 11 peaks are illustrated in Fig. 2. Peaks 0,1 , and 3 are possible unidentified contaminants. Peaks 2 and 4 are 2,2',4,5,5'pentabromo-1, $1^{\prime}$-biphenyl (PnBBa) and 2,3',4,4',5-pentabromo-1, $1^{\prime}$-biphenyl(PnBBb), respectively. Peak $4^{\prime}$ is a hexabromo-1, $1^{\prime}$-biphenyl ( $\mathrm{HxBBa}$ ) whose bromine positions are yet to be assigned. Peak 5 is $2,2^{\prime}, 4,4^{\prime}, 5,5^{\prime}$-hexabromo-1, $1^{\prime}$-biphenyl (HxBBb). Peak 6 is $2,2^{\prime}, 3,4,4^{\prime}, 5^{\prime}$-hexabromo-1, $1^{\prime}$-biphenyl (HxBBc) and peak 7 is $2,3^{\prime}, 4,4^{\prime} 5,5^{\prime}-$ hexabromo-1, $1^{\prime}$-biphenyl (HxBBd). The heptabromobiphenyls appear as peaks 8, 9 and 10 , known as $\mathrm{HpBBa}, b_{\text {, and }} \mathrm{c}$, respectively; $\mathrm{HpBBb}$ is $2,2^{\prime}, 3,4,4^{\prime}, 5,5^{\prime}$-heptabromo-1,1-biphenyl.

Typical molecular ions of the PBBs can be noted in the spectra in Fig. 2. For example, the lowest molecular ion $x$ should be the sum of ${ }^{12} \mathrm{C},{ }^{1} \mathrm{H}$ and ${ }^{79} \mathrm{Br}$, which, for HxBBb, is 622. The number of additional molecular ions is the sum of the bromines'. Especially interesting is that chlorine contaminants are observed in many of the PBBs. For example, HxBBb (peak 5$)$ has the expected molecular ions $(622,624,626,628$, 630,632 , and 634). The [M - $\left.{ }^{79} \mathrm{Br}\right]$ groupings $543,545,547,549,551$, and 553 a.m.u. are also observed. However, an unexpected set of ions $(578,580,582,584,586,588$ and 590 a.m.u.) occurs in the spectrum of HxBBb. An enlargement of the [M] and $\left[\mathrm{M}-{ }^{79} \mathrm{Br}\right.$ ] ions of peak 5 is shown in Fig. 3; similar analyses can be done for the other peaks. The analysis of relative abundances of the mass spectrum of peak 5 is consistent with a pentabromomonochlorobiphenyl contaminant that has a GC retention time similar to that of $\mathrm{HxBBb}$. Capillary column separation of the various compounds in FF-1 is an essential task for the future. It can be observed in the mass spectra of Fig. 2 that many of the PBBs have minor chlorine contaminants. To our knowledge, we are

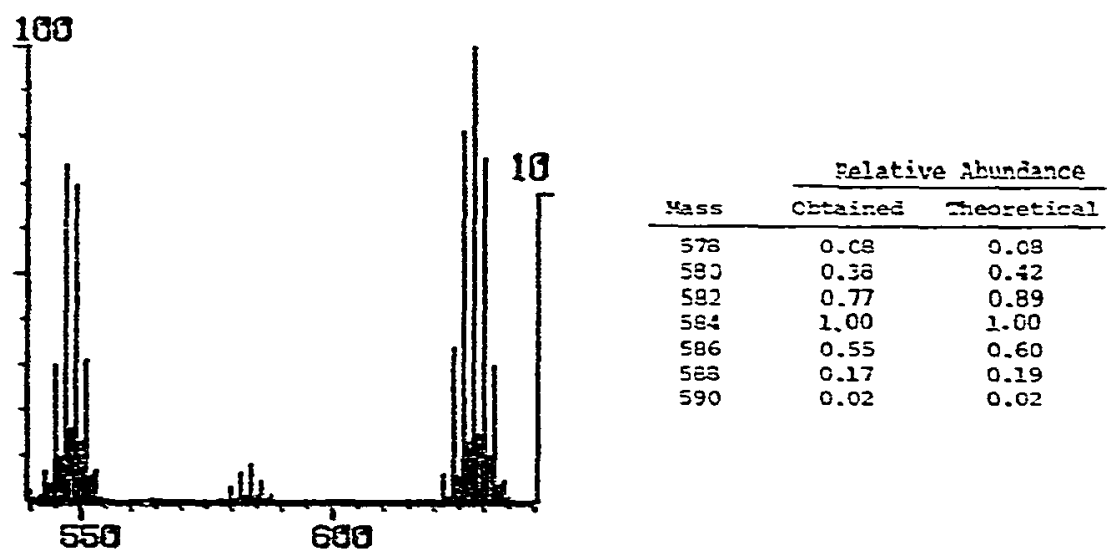

Fig. 3. Enlargenent of the [M] and [M - "Br] molecular ion spectra of the major hexabromobiphenyl of Furemaster FF-1 indicating a pertabromomonochlorobiphenyl contaminant. Note that the obcained and theoretical abundances of the various molecular ions for a pentabromununochlorobiphenyl contaminant are similar. The theoretical abundance for a $\mathrm{ClBr}_{s}$ compound was obtained from Beynon et al." and calculated with mass 584 as 1.00 . 
the first to point this out, although it is certainly expected that minor amounts of chlorine will contaminate commercial bromine.

\section{ACKINOWLEDGEMENTS}

The authors would like to thank Mr. Benjamin Mathews for his assistance. This work was supported in part by a grant from the Michigan Department of Public Health and the Psychopharmacology Research Fund (S.E.D.).

\section{REFERENCES}

1 G. Sundstrom, O. Hutzinger, S. Safe and V. Zitko, Sci. Total Environ., 6 (1976) 15.

2 J. J. De Kok, A. De Kok, U. A. Th. Brinkman and R. M. Kok, J. Chromatogr., 142 (1977) 367.

3 L. W. Jacobs, S. Chou and J. M. Tiedje, J. Agr. Food Chem., 23 (1976) 1198.

4 G. A. Dannan, R. W. Moore and S. D. Aust, Environ. Health Persp., 23 (1978) 51.

5 L. B. Willett, C. J. Brumm and C. L. Williams, J. Agr. Food Chem., 26 (1978) 122.

6 K. Kingsley, Environ. Res., 13 (1977) 74.

7 GCIMS Data System Operation Manual, Revision H, Finnigan, Sunnyvale, CA, 1975, pp. 2-17. 8 J. W. Eichelberger, L. E. Harris and W. L. Budde, Anal. Chem., 47 (1975) 995.

9 J. H. Beynon, R. A. Saunders and A. E. Williams, The Mass Spectra of Organic Compounds. Elseyier, New York, 1968, pp. 1-510 